\title{
Paisajes culturales del regadío tradicional e histórico en la Vega Alta de Segura
}

\author{
Encarnación Gil Meseguer \\ Departamento de Geografía.Universidad de Murcia. \\ encargil@um.es
}

\begin{abstract}
Resumen. El uso del agua para riego, en el tramo alto del Valle de Segura, ha creado una serie de paisajes culturales que responden a las condiciones del medio y al interés agronómico de los grupos humanos. La huella de esta actividad de cultivo en regadío, a lo largo de varios siglos, es una sucesión de paisajes como los arrozales de Salmerón, Cañaverosa y Calasparra; las huertas tradicionales del fondo del valle, como las del valle de Ricote (oasis de palmeras y cultivos de vuelo y suelo, policultivo) y, los regadíos escalonados en las laderas del valle con monocultivo de frutales de hueso (como albaricoque, melocotón, ciruela, etc.) o de frutales cítricos (como limón, naranja, mandarina, etc.). Estos paisajes de las hoyas y cubetas del Segura, se han visto amenazados por la expansión urbana de los núcleos de población, situados siempre en su inicio en piedemontes y terrazas fluviales en el lóbulo de un meandro del río (Cieza, Abarán, Blanca, Ojós, Villanueva, etc.), para alejarse de las periódicas inundaciones del valle y, a la vez, dejar las mejores tierras, por su suelo y accesibilidad al agua, para el cultivo.
\end{abstract}

También los paisajes creados a partir de puntos de emisión como fuentes y manantiales, caso de la Fuente Grande de Ricote o La Fuente del Ojo en Cieza. A los que se unen los oasis mediante pequeñas captaciones de acuíferos con pozos verticales y horizontales. En el caso de la elevación se lleva a cabo por norias de tiro o de sangre y artes y norias de cremallera, y el alumbramiento por gravedad mediante galerías (qanates, minas de agua y socavones).

Los cambios en los paisajes rurales se dan ante nuevas condiciones económicas para el sector hortofrutícola en el siglo XX: el Plan de Estabilización de 1956, el éxodo rural y la emigración de los años sesenta y setenta, el Acuerdo Preferencial con la CEE de 1970, o el Tratado de Adhesión del Reino de España a la Unión Europea. El siglo XXI plantea nuevos retos relacionados con las producciones de denominaciones de origen y con los productos de identidad geográfica, con proyectos de modernización de regadíos y valorización del patrimonio hidráulico, y con la multifuncionalidad del mundo rural al compatibilizar la actividad agraria (a veces a tiempo parcial) con otras de ocio y recreación, como el turismo rural.

Palabras clave: Paisaje, oasis, policultivo, frutales, cítricos, riego bajo acequia, riego por elevación, nuevos regadíos.

\begin{abstract}
Cultural landscapes in traditional and bistorical irrigation in La Vega Alta de Segura. The use of water for irrigation in the high course of the Segura Valley has created a series of cultural landscapes that respond to the conditions of the environment and the agronomic interest of human groups. The result of this crop irrigation activity, over several centuries, is a succession of landscapes, such as the rice fields of Salmerón, Cañaverosa and Calasparra; the traditional irrigated fertile regions (buertas) of the valley floor, such as the Ricote Valley (oasis of palm trees and above-ground and ground crops, mixed cropping), and the stepped irrigation on the valley slopes with monoculture plantations of stone fruit trees (for example, apricot, peach, plum, etc.) or citrus fruits (for example, lemon, orange, mandarin, etc.). These landscapes of the Segura vales and basins are threatened by the urban sprawl of population centres, always initially located in foothills and river terraces in a river meander loop (Cieza, Abarán, Blanca, Ojós, Villanueva, etc.), in order to avoid the periodic flooding of the valley, and, at the same time, leave the best land, for its soil and accessibility to water, for growing crops.
\end{abstract}

Likewise, the landscapes created from points like sources and springs, as in the case of La Fuente Grande in Ricote or La Fuente del Ojo in Cieza. As well as oases through small aquifer catchments with vertical and horizontal wells. In the case of lifting, it is done by different styles of water wheels, and collecting systems by gravity through galleries (qanats, mine water and subsidences).

Changes in rural landscapes occur due to new economic conditions for the fruit and vegetable sector in the 20th century: the 1956 Stabilization Plan, the rural exodus and emigration in the 1960s and 1970s, the 1970 Preferential Trade Agreement with the EEC, or Spain's Treaty of Accession to the European Union. The 21st century poses new challenges related with appellation of origin productions and geographical identity products, irrigation system modernization projects, valuation of water heritage, and the multifunctionality of rural areas when making the agricultural activity (sometimes part-time) compatible with leisure and recreation activities, such as rural tourism.

Key words: Landscape, oasis, mixed cropping, fruit trees, citrus trees, low channel irrigation, lift irrigation, new irrigation. 


\section{Objetivos y metodología.}

Entre los objetivos de este trabajo de investigación sobresale explicar los paisajes culturales construidos en una relación hombre medio de aplicar el riego en la Vega Alta del Segura en los últimos cuatrocientos años (desde la expulsión de los moriscos, en 1613, hasta hoy) atendiendo a los modelos de sangrado del Segura por azud y acequia, y el de aprovechar puntos de emisión de agua como fuentes y manantiales.

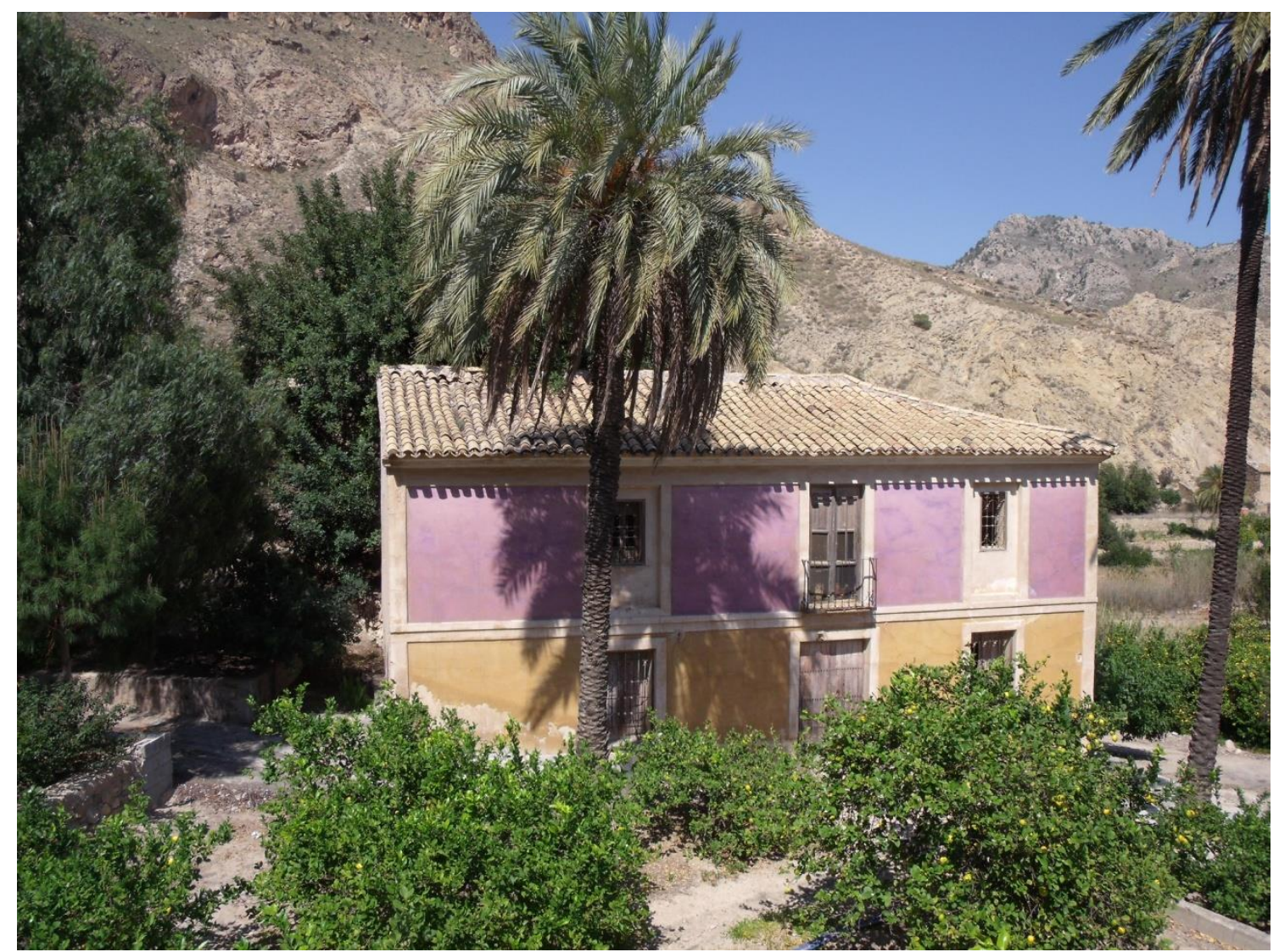

Fig.1. Imagen del hábitat disperso en las huertas del Valle de Ricote.

Se aborda el estudio desde el manejo del agua a nivel local o subregional (Palerm Viqueira 2002; Palerm Viqueira y Martínez Saldaña, 2000 y 2009); del aprovechamiento integral del agua y del dinamismo-mutaciones del regadío (Gómez Espín, 2004; Gil Meseguer et al., 2014); del papel del sistema azud-acequia como comunidad de usuarios (Rivera, 2009); del regadío histórico y su patrimonio material e inmaterial (Glick, 1988; Hermosilla, 2010), y de la organización social mediante prácticas de gobernanza de heredamientos y comunidades de regantes fijadas en sus Ordenanzas y Reglamentos (Maass y Anderson, 2010).

La metodología utilizada es la propia de la Geografía Regional y la Ordenación Territorial, entendiendo, el término paisaje, como lo define el Convenio Europeo del Paisaje, es decir: "Cualquier parte del territorio, percibida por la población, cuyo carácter resulta de la acción de los factores naturales y humanos y de sus interrelaciones". En el análisis, diagnosis y prognosis se han empleado el trabajo de campo, la labor de búsqueda y consulta de documentación en archivos, y las entrevistas a gestores y usuarios del agua para riego. 


\section{Rasgos del Valle fluvial y su entorno.}

El rio Segura desde su nacimiento hasta entrar en la Región de Murcia, va adaptándose a los relieves prebéticos del sur de la provincia de Albacete. Circula con dirección del SWNE que, a partir del embalse de la Fuensanta, cambiará por E- W y de nuevo al salir del embalse del Cenajo a casi N-S. En todo este recorrido discurre entre sierras umbrosas pobladas de pinos sobre todo en las umbrías, donde el valle es de reducida amplitud e incluso encajonado entre las vertientes. La escasa población de este interior serrano y las temperaturas invernales frías, no han favorecido ocupaciones intensivas de los escasos terrenos cultivados a partir de pequeñas derivaciones de agua. Después de la salida del Cenajo el rio es frontera entre Albacete y Murcia, y va cortando los relieves prebéticos como el Cerro de los Castillicos $(847 \mathrm{~m})$ lo que origina una sucesión de tramos encajados y estrechos, y pequeños sectores de sedimentación neógena que ganan en amplitud y donde el hombre ha ordenado el espacio para el cultivo. En los estrechos rocosos se construyeron presas transversales en el cauce, azudes, para derivar agua lateralmente por canales de débil pendiente, acequías, que la llevan a las parcelas que quedan por debajo de ellos para su riego por gravedad. El mayor espacio puesto en riego en el tramo común a las dos provincias, es el paraje de Salmerón y Minas, y ya en Murcia, desde el azud de la Peraleja continua hasta llegar al azud de Cañaverosa, donde tradicionalmente comienza lo que se conoce como Vega Alta del Segura. Este espacio, unos 147 kilómetros de longitud, se prolonga hasta el Azud de la Contraparada, a partir de dónde se inicia la Huerta de Murcia y la Vega Media.

Tras Cañaverosa, una vez el Rio ha cortado los relieves prebéticos de la sierra del Puerto, sigue una dirección de W-E al ajustarse a la alineación de la sierra del Molino por su derecha, mientras que a su izquierda se extiende el valle de inundación y los glacis que descienden desde la sierra del Puerto-Cabeza del Asno y cubren las margas de la cuenca neógena-cuaternaria que comienza en Calasparra y, ocupa mayoritariamente el municipio de Cieza. Las sierras subbéticas del Oro y Ascoy, con dirección NE-SW, cierran la cuenca ciezana hacia el SE, por lo que el Rio corta estos relieves al cambiar su dirección de NW a SE. Y va a hacerlo con todas las alineaciones subbéticas que se suceden de norte a sur, originando lo que se ha caracterizado como un valle en "rosario". Es la manera de describir la alternancia de estrechos y, hoyas y cubetas que se van a formar a lo largo del recorrido del Segura. En los estrechos se instalan los azudes, de donde parten las acequias que dan riego a las huertas que se construyen en las cubetas.

Después de la amplia cubeta de Cieza, sigue la Hoya de Don García, la de Abarán seguida de Blanca, y a partir del estrecho del Solvente el valle se estrecha entre paquetes calizodolomíticos de las sierras de Ricote y del Cajal lo que deja una estrecha banda para los cultivos. Es a partir de Archena que vuelve a ampliarse al penetrar en la cuenca neógenacuaternaria, que desde sierra Espuña al SW, se alarga de NE-SW hasta la sierra de Barinas y el Cantón, interrumpida por relieves monoclinales y alguna cresta. Las huertas de Archena, Lorquí, Ceutí, Alguazas, Torres de Cotillas y Molina, se extienden sobre este espacio sin solución de continuidad. Esta cuenca está limitada y separada de la depresión prelitoral murciana por los relieves miocenos de la sierra de la Muela, del Cura y los afloramientos béticos del alpujárride que aparecen desde Murcia a Santomera. 


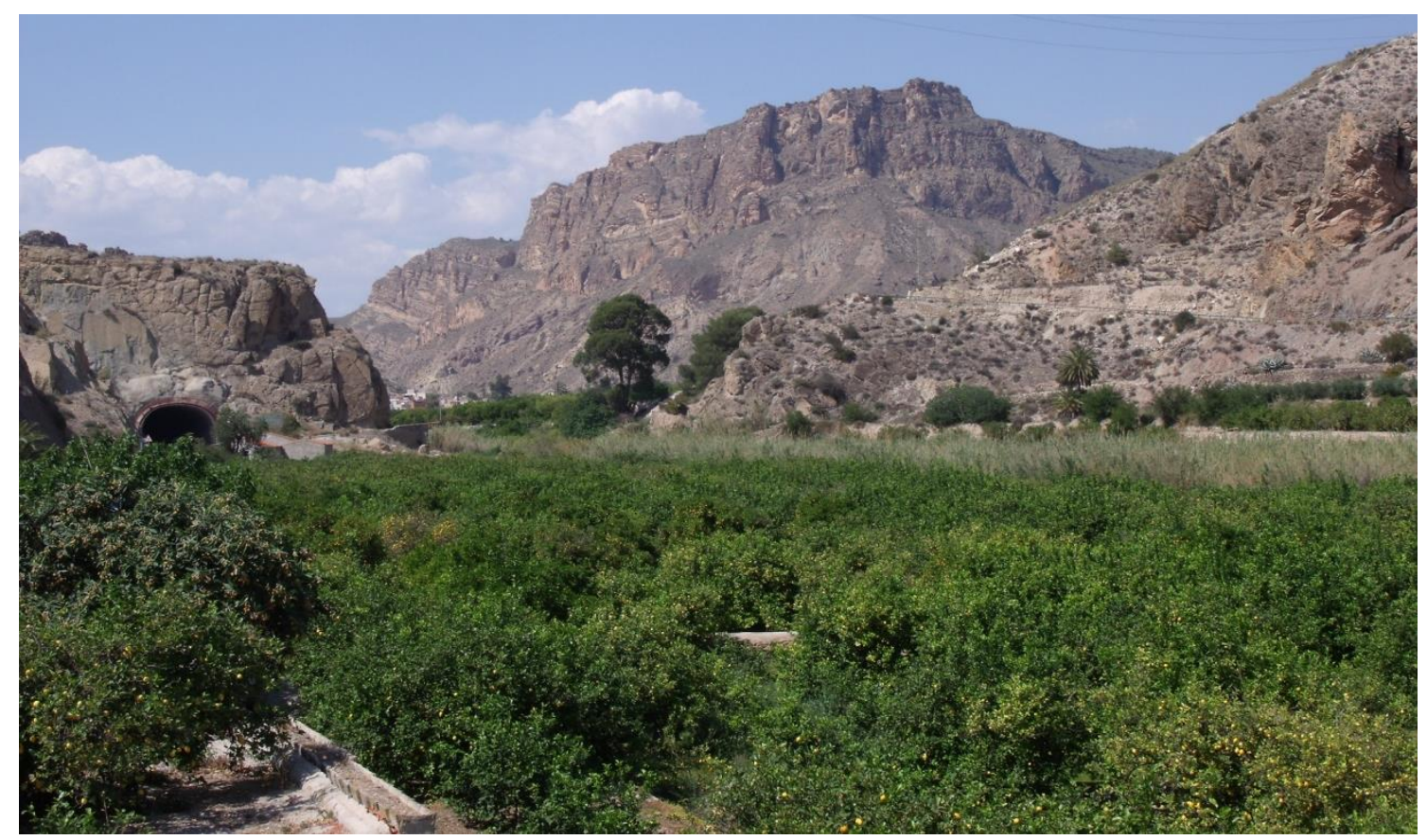

Fig.2. Estrecho del Salto de la Novia en el valle de "rosario" del tramo alto de Segura.

\section{Paisajes del sangrado de Segura mediante sistemas de azud y acequia.}

El sangrado del Segura comienza desde su cabecera para poder cultivar todo el año en las huertas, que a partir de la salida del embalse del Cenajo y de su entrada en la Región de Murcia, van a alcanzar la máxima amplitud y un aprovechamiento intensivo para la obtención de rendimientos económicos.

Los primeros paisajes que se originan son los que constituyen lo que se llama Coto Arrocero de Calasparra, regado con aguas del Mundo y del Segura, que incluye tierras del municipio albaceteño de Hellín (790 ha potenciales) y el murciano de Moratalla (149 ha) además de Calasparra (970 ha) que le da nombre. Estos paisajes son el último reducto del cultivo de arroz que existió, en tiempos pretéritos, a todo lo largo del Segura en sus parcelas más inmediatas. La "insalubridad” por la proliferación de mosquitos y la aparición de fiebres tercianas en los lugares de cultivo, coincidiendo con áreas densamente pobladas, ocasionó su prohibición y el retroceso hacia las tierras más altas y frescas y, también menos pobladas. Aquí, ajustándose al cauce del rio y hasta las acequias, que les suministran el agua derivada aguas arriba en los azudes, y que se sitúan a la mayor altitud posible por el borde de los relieves para conseguir la máxima superficie de riego, aparece una retícula de parcelas rectangulares inundadas gran parte del año. Estas parcelas están escalonadas siguiendo la pendiente del rio y hacia él, puesto que aquí el cultivo se hace con el riego tradicional de circulación constante de agua entre las parcelas, que en última instancia desagüan en zanjas de drenaje o el rio. Los agricultores justifican este sistema para que el agua se "vaya calentando" progresivamente al pasar de una a otra parcela. Las parcelas o "cajas" están dibujadas por los caballones o lindes, los canales de riego o los de drenaje. Tras la preparación de la tierra a finales de abril, en los inicios de mayo se siembra y las parcelas seguirán inundadas hasta septiembre o principios de octubre en que se procede a la recolección. Se pasa así por las etapas de lámina de agua, alfombra verde intenso y campos dorados. 
En estos espacios el arroz es cultivo sometido a rotación, de manera que durante un año la tierra descanse de ese cultivo, para "reponerse" antes de comenzar otra vez. Aquí suele seguirse un calendario que va de mayo a octubre con arroz, de noviembre a junio con trigo y de julio a abril se plantan leguminosas que en el cultivo ecológico se utilizan como abono verde. Son estas parcelas las que rompen la continuidad del paisaje inundado, pues aunque las hay con cultivos arbóreos como frutales de hueso y algunas con chopos para la explotación maderera, son pocas en el valle de inundación. Por encima del nivel de las acequias, en cotas de mayor altitud, si son los frutales los que se han instalado siempre que exista riego, porque si no es así ya es el espacio para el secano, con olivos fundamentalmente.

Una vez fuera del término de Calasparra, después de que el Segura haya cortado la sierra del Molino con el largo estrecho de Almadenes, comienza la Huerta de Cieza. Es una parte de la amplia cuenca de Cieza pero se circunscribe a una banda a ambos lados del Segura, con tanta amplitud como dejan las acequias de D. Gonzalo y Andelma (margen derecha) y del Horno y Los Charcos (margen izquierda) hasta el cauce del rio. Las parcelas son estrechas, largas y perpendiculares al rio, dibujando el lecho de inundación. Las divisiones por herencia explican la estrechez, sobre todo en la cercanía al núcleo de Cieza, mientras que las más alejadas, hacia Almadenes, son algo más amplias e incluso han sido unidas bajo un mismo propietario para buscar el tamaño adecuado para la explotación con fines comerciales. La huerta tradicional, la de parcelas de reducidas dimensiones está ocupada todo el año con gran variedad de cultivos. A los cultivos frutales, sobre todo de hueso, se le unen o superpones en la misma parcela cultivos hortícolas y forrajes. No existe hábitat disperso, lo que se ve en la pequeña construcción para los aperos y alguna de mayor tamaño para acoger visitas ocasionales de corta duración. Es el mismo paisaje de la huerta de Abarán bajo riego a pie, sólo que aquí ya aparecen cítricos, alguna variedad de naranja o mandarina y algún limonero para el consumo doméstico, pues las temperaturas invernales y la inversión térmica del fondo del valle desaconseja este cultivo (es en Blanca, en la Huerta de Arriba donde aparecen más regularmente hasta formar plantíos).

Entre Abarán y Blanca, los frutales cubren las parcelas inmediatas al rio y, a partir de Blanca, su tradicional Huerta de Abajo ha sido inundada por las aguas del embalse que forma parte de la infraestructura del post-trasvase Tajo Segura. Por encima del nivel de las aguas, son los frutales de hueso y cítricos los que forman el paisaje. Los cultivos hortícolas ocupan escasas parcelas o, comparten el espacio con los frutales. Así va a seguir siendo el paisaje hasta Archena, pues lo reducido del terreno en el estrecho valle que pertenece a Ojós, Ulea y Villanueva del Rio Segura, lo que crea es la visión de "oasis" en los que las palmeras sobresalen sobre el continuo de los frutales, el rio se dibuja por las cañas que lo jalonan y, las resecas y despobladas vertientes de calizas y dolomías que taja el rio los enmarcan. A partir de Archena (Ceutí, Lorquí, Alguazas, Molina de Segura), la amplitud del espacio crece. Los relieves se retiran del rio o son de menor envergadura (relieves miocenos de margas, areniscas y calizas), pero la huerta tradicional sigue siendo una "cinta" de parcelas pequeñas, que tiene más o menos anchura en una u otra margen del rio dependiendo de la cercanía de cabezos, cerros y montículos donde se asentaron las poblaciones para alejarse del peligro de inundaciones y, dejar el mayor terreno posible para ser regado por inundación desde las acequias. El crecimiento urbano en parte ha invadido este espacio, pero generalmente se ha dirigido hacia el "traspaís" alejado del rio, junto con la ocupación industrial y de servicios. La presión demográfica ha servido para que una vez que el reducido tamaño de las parcelas y, los cambios socioeconómicos, hizo económicamente inviable su cultivo, se transformaran en "parcelas jardín" donde se practica una agricultura a tiempo parcial de "subsistencia" o una agricultura de "ocio". Frutales de hueso, cítricos, hortalizas, y tubérculos, en todas las combinaciones posibles, 
explican los paisajes de estas huertas tradicionales. Donde además se está dando una modernización del regadío por inundación a otro localizado por goteo para facilitar compatibilizar esa agricultura de ocio con la ocupación principal del explotante, también la exigencia de una mayor eficiencia en el uso del agua demandada por los Administradores del Agua. Esto también ha ocasionado que a favor de la disponibilidad de agua y, la cercanía de importantes núcleos de población, se haya visto desarrollarse una agricultura para el comercio local de productos hortícolas (patatas, lechugas, coles, coliflores etc), a partir de parcelas propias y alquiler de las inmediatas, e incluso puesta en cultivo de parcelas abandonadas. En estos terrazgos, las pequeñas agrupaciones de casas que existían fuera de la cabecera municipal, se han hecho mayores por el crecimiento de la población y también por albergar servicios e incluso instalaciones industriales. Además, han aparecido pequeñas construcciones para aperos o viviendas ocasionales, que en algún caso son segundas residencias y ocupan parte de la primitiva parcela de uso agrícola.

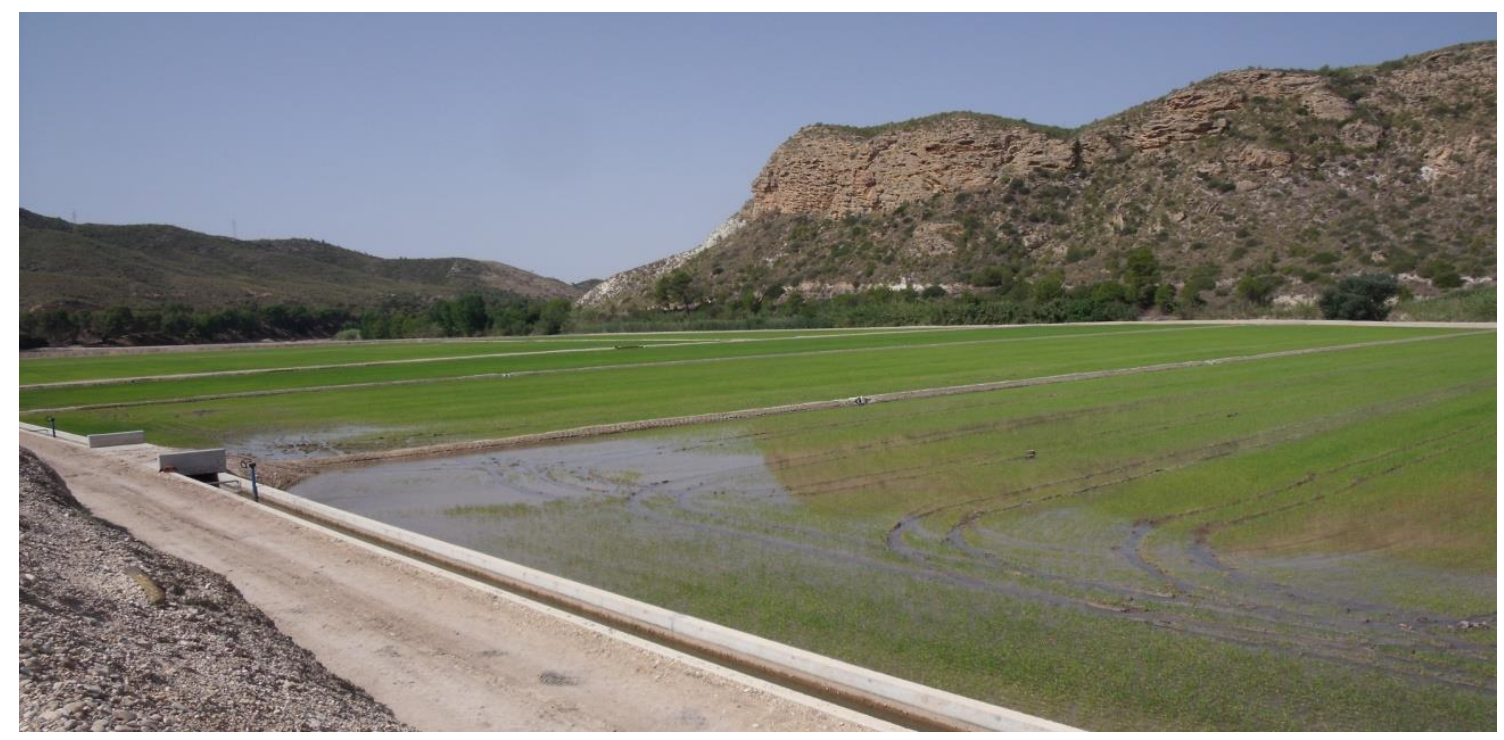

Fig.3. Paisaje de arrozal bajo riego de la acequia del Peralejo en la M.I. de Segura.

\section{Paisajes del riego por elevación en las laderas del Valle.}

Con las condiciones climáticas de semiaridez que caracterizan este espacio, el agua es imprescindible para asegurar cultivos y producciones. Esto explica la apetencia de llevarla a las tierras inmediatas a las ya regadas. Cuando además lo estrecho del valle, hace que sean escasos los terrenos para la presión demográfica que reciben. Por encima del nivel de las acequias que posibilitan el riego, hay disponibles otras tierras que estarían acondicionadas para el cultivo de secano. La naturaleza impermeable y poco resistente a la erosión, que caracteriza las margas neógenas que rellenan las cubetas y cuencas, que quedan entre las alineaciones montañosas que atraviesa el rio Segura, obligaría a los hombres a aterrazar esas laderas. Es la forma de evitar la erosión de la capa superficial de suelo tras fuertes precipitaciones, de impedir que la escorrentía incida abarrancando y destruyendo los cultivos, también de facilitar la infiltración y acumular agua en el suelo, lo que también favorece la formación de suelo. Incluso se construirían muretes de piedra seca (hormas) para sostener el aterrazamiento y evitar su destrucción. Sólo faltaba llevarles el agua para su puesta en riego. La instalación de aparatos elevadores de agua sobre las acequias que limitan la huerta del secano, es la respuesta a esa necesidad. 
La instalación de ruedas de corriente baja, con cangilones en una o en las dos coronas (norias), o de norias de tiro o de sangre (ceñas) fue capaz de ampliar el área regada en más de 2000 tahúllas (medida de superficie en Murcia de $1118 \mathrm{~m}^{2}$ ). En 1929, según el censo de norias desde el Salmerón a la Contraparada era de 153 ingenios, con posibilidad para regar 2.979 tahúllas (algo más de 333 ha). Hacia finales del siglo XIX algunos de estos ingenios son sustituidos por motores que son capaces de elevar más alto y más agua. Es el camino que se va a seguir conforme los avances técnicos pongan a disposición motores con cada vez más potencia de elevación que implica la posibilidad de ampliar el área regada. Aún así no fueron sustituidos todos los aparatos y aún hoy forman parte del paisaje y cumplen su función para la que se instalaron, caso de las norias de Abarán (cuatro en funcionamiento).

Los paisajes que van a aparecer en un primer momento serian posiblemente los de un secano mejorado con árboles frutales, de hueso y cítricos, pero sin formar grandes plantaciones, pues hasta la regulación del Segura con la construcción de los grandes embalses, sobre todo el Cenajo, estos regadíos elevados no tendrían asegurado el riego todo el año y todos los años. Las tierras más cercanas al fondo del valle, las que antes se regaron, también son las que se convierten en plantaciones de frutales cuyas cosechas tienen asegurado un mercado que se amplía progresivamente, además de originar una industria conservera.

Toda la Vega Alta, desde la entrada del Segura en la Región y compartiendo con el espacio albaceteño (Hellín), es el dominio de plantaciones de frutales de hueso, ciruelas de distintas variedades, albaricoque (búlida y nuevas variedades), melocotoneros, e incluso algún parral de uva de mesa en las inmediaciones de Abarán. Los suelos y las temperaturas más frías, no son favorables a los cítricos por encima de Cieza, incluso retroceden hasta ser residuales en esta localidad y en Abarán, para tener presencia importante y continua desde la Huerta de Arriba de Blanca, hasta la Contraparada. Los frutales de hueso comparten al terrazgo con ellos y no desaparecerán hasta la Huerta de Murcia, donde por el contrario aquí serán residuales y los cítricos se convierten en un casi monocultivo.

Es en estas tierras de riego por elevación donde aparecen grandes fincas especializadas en estos frutales, con casas señoriales. Sólo se ha producido abandono de parcelas por las dificultades de acceso y lo reducido de su tamaño que las ha hecho inviables en las condiciones actuales. Pero una serie de condiciones de calidad ambiental por la orientación de las vertientes, ausencia de heladas de inversión etc, mantienen aún esos paisajes. Desde ellos, y con su ejemplo, se han dado las grandes transformaciones en regadío a partir de las aguas subterráneas profundas y la llegada de las aguas del Trasvase Tajo-Segura. A lo largo del año se pasa de las laderas "en leña" características de una arboricultura de hoja caduca, a unas laderas floridas en gamas de blanco, rosas y morados, a un manto verde moteado del color de la fruta. Donde los cítricos, es el verde continuo salpicado de azahar y después de naranja y amarillo. En medio de estos espacios algunas viviendas tradicionales, unas veces sin restaurar, otras transformadas como segunda residencia. También otras construidas con ese fin y con la introducción de todos aquellos elementos que la sociedad entiende como signos de prosperidad. 


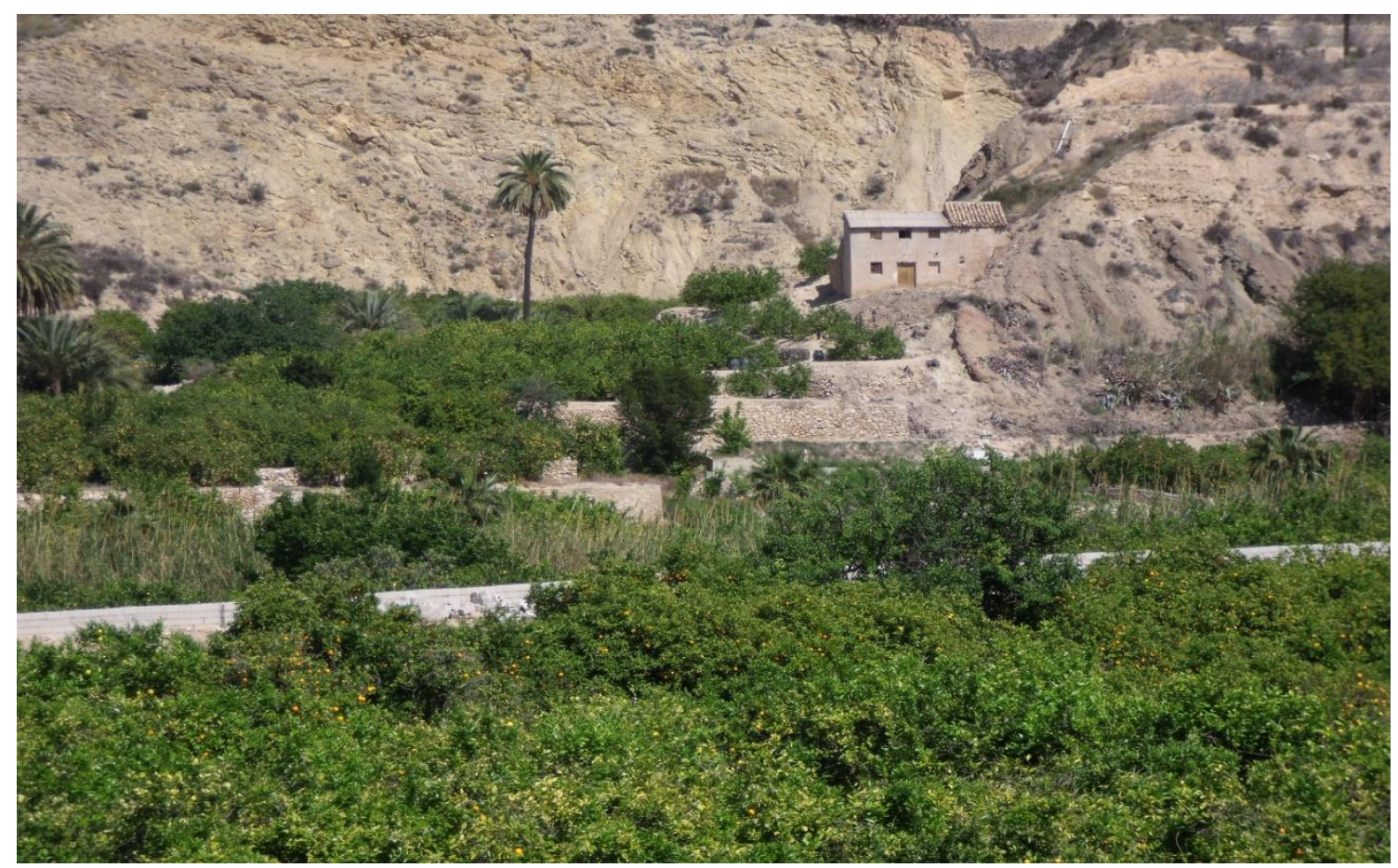

Fig.4. .La conquista de las laderas del Valle. Hormas, terrazas y ruedas hidráulicas escalonadas.

\section{5 “Oasis" de fuentes y manantiales.}

En el tramo alto del Valle de Segura y en sus inmediaciones existen toda una serie de espacios regados que reflejan esa imagen de huerta de oasis. La huerta de Ricote es uno de los ejemplos más significativos, organizada desde tiempo inmemorial a partir de las aguas de "La Fuente Grande o del Molino". Manantial que aflora mediante minado (galería) a 386 metros sobre el nivel del mar, de un acuífero "Vega Alta", entre las sierras de Ricote y del Oro, en la margen derecha del río. La altitud de la bocamina y de la balsa de acumulación de agua, permite que por gravedad pueda regarse casi toda el espacio que llamamos Huerta de Ricote. (Desde 1985 el aprovechamiento está inscrito en el Catálogo de aprovechamientos privados de la Cuenca de Segura, con un caudal de 14 litros por segundo, y coordenadas UTM. X: 642322 e Y: 4223621).

El Heredamiento, en Junta General de 4 de abril de 1909, acordó la formación de un Proyecto de Ordenanzas y Reglamentos, que fueron aprobados el 6 de mayo de 1922. En ellas se fija que es propiedad del Heredamiento la mina dónde aflora el manantial a superficie, la balsa de acumulación del agua, y las canalizaciones para su distribución a las parcelas de cultivo. El artículo 11 indica que: "Cada propietario integrado en el Heredamiento, tiene derecho a la cantidad de agua, dentro de cada tanda, que con sujeción a lo fijado en sus títulos de propiedad, dominio o posesión inmemorial, les corresponda. Esta cantidad está referida sólo al computo horario (horas, minutos, y segundos), y no al caudal que fluya, ya que puede experimentar cambios en función de las condiciones climáticas ". Según el artículo 14 de las Ordenanzas: "el riego se distribuye en tandas de 14 días cada una, por lo que poniendo 24 horas diarias, cada tanda contiene 336 horas. La tanda comienza a las 7 de la mañana y concluye a las 7 de la tarde...". Para regar en cada tanda, el agua se subdivide en dos hilas: la llamada "Hila del Molino", que a partir de las 7 de la mañana no vierte a la balsa y la "Hila de la Balsa" que, desde la misma hora, comienza 
su desembalse o vaciado de la que ha venido recibiendo del nacimiento a partir de las 7 de la tarde del día anterior. Es decir una riega directamente con el agua que está alumbrando desde las 7 de la mañana a 7 de la tarde "hila de día", y otra con la cumulada en la balsa desde las 7 de la tarde a 7 de la mañana "hila de noche". En estos riegos de manantial de aforo escaso la propiedad de la tierra y del agua suelen estar separadas, el heredero es propietario de un tiempo en una tanda, y según sus necesidades e intereses puede aprovecharlas en su finca dentro de la zona de riego o cedérsela (incluso venta) a otro usuario interesado.

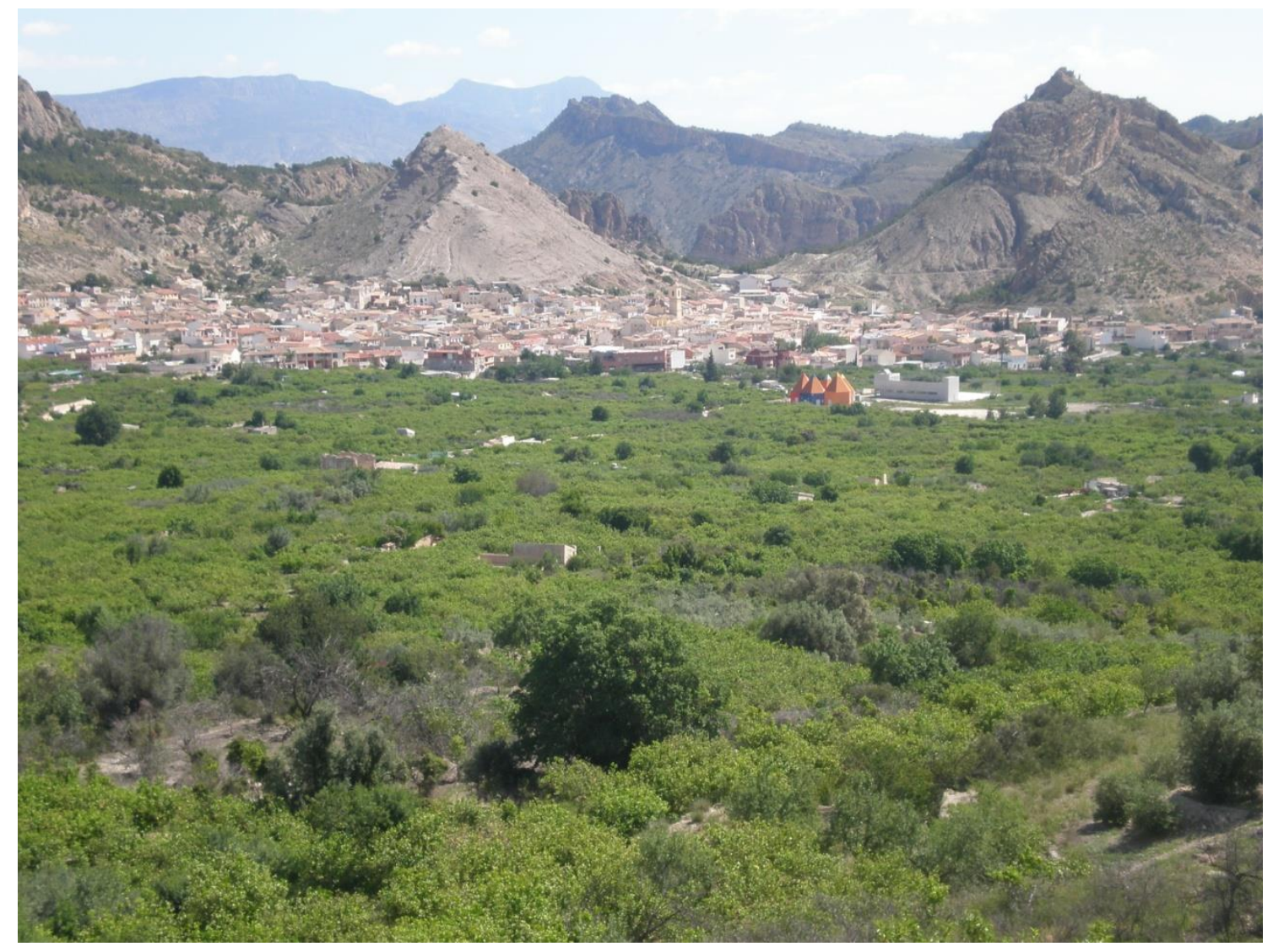

Fig.5. La huerta-oasis de Ricote. Inicialmente basada en las aguas de la Fuente Grande o del Molino, completada con una dotación de aguas elevadas desde el río Segura.

Según el Catastro de Ensenada, en 1755, en Ricote las tierras de regadío significaban algo menos de la superficie total del término, eran 108,66 ha las que podían regarse con las aguas de Fuente Grande o del Molino, y de oros pequeños subálveos como Paúl o las Balsas. El agua se compartía para el riego, para el abastecimiento de ganados y personas, para usos industriales (molino de cubo) y para usos domésticos (lavaderos).

El artículo 47 de las Ordenanzas indicaba: "las aguas tienen como finalidad esencial el riego de las fincas, no obstante y excepcionalmente, según usos y costumbres consentidos desde siempre, pueden servir además: para apagar incendios, obras y edificaciones, baños, replante de árboles, aseo y limpieza de viviendas, enseres domésticos y ropas, así como abrevar el ganado". 
Este espacio regable dependiendo casi exclusivamente de las aguas de la Fuente Grande o del Molino, no podía ampliarse. De ahí que aprovechando la regulación de los riegos de Segura, según el Decreto de 25 de Abril de 1953, se solicite por el Ayuntamiento de Ricote una concesión de aguas públicas para abastecer suficientemente el regadío de esta huerta (30 litros por segundo del río Segura en el periodo entre el 15 de octubre de cada año y el 15 de junio siguiente, la aprobación de las obras es del 6 de septiembre de 1957). El 19 de octubre de 1964 se constituye la Comunidad de Regantes de la Huerta de Ricote, que solicita una ampliación de la dotación de Segura y el 15 de noviembre de 1974 se les concede pasar de 30 litros por segundo a 49 litros por segundo). El espacio regable reúne el tradicional regado con aguas del Heredamiento y unas ampliaciones hasta las casi 200 ha (188,2 ha regadas en el 2012). Según se tengan o no derechos a las aguas del Heredamiento nos encontraremos quienes riegan con sólo las del Heredamiento, con las de la Comunidad de Regantes, o con las dos. Buena parte de este oasis, de huerta predominantemente citrícola, de pequeñas parcelas de explotación (unas 2.400), se ha sometido recientemente a un proceso de modernización su sistema de riego, pero conservando las canalizaciones tradicionales, hay quien riega mediante el sistema de riego localizado (unas $130 \mathrm{ha}$ ) y quien lo hace todavía por inundación.

\section{El manejo del agua. Gobernanza de heredamientos y comunidades de regantes.}

El sistema de azud-acequia en un cauce fluvial exige de una organización social para la gestión de agua. Bajo la forma de heredamiento regante o comunidades de regantes, todos los usuarios-regantes de una misma toma acostumbran a someterse a unas ordenanzas y reglamentos para resolver los posibles conflictos en la distribución del agua y en el mantenimiento de las obras para hacer posible el riego. A veces se han organizado como sociedades civiles de bienes con el fin de establecer algún artilugio de elevación de aguas para riego incluidos los modernos electromotores. Todos son corresponsables en la organización social y gestión del agua (gobernanza).

Las Ordenanzas del Heredamiento Regante de Molina de Segura (Murcia) y los Reglamentos del Sindicato y del Jurado de Riegos de 1935 a lo largo de su artículado ponen de manifiesto la forma de organizarse, quienes forman la comunidad, cómo resolver los conflictos, quienes tienen derecho al agua, etc. Artículo $1^{\circ}$ : "Los propietarios de los terrenos comprendidos en las zonas regables y los dueños de los molinos y fábricas que tienen derecho al aprovechamiento de las aguas que discurren por la acequia de este término municipal, que toman del río Segura, en el término de Archena, partido rural de la Algaida, por su margen izquierda, para el riego de sus tierras, radicantes todas ellas en dicha margen izquierda del indicado río y términos jurisdiccionales de Archena, Lorquí, Molina de Segura y Murcia, se constituyen en comunidad de regantes bajo la denominación de Heredamiento Regante de Molina de Segura, en virtud de lo dispuesto por el artículo 228 de la Ley de Aguas de 13 de junio de 1879”.

La comunidad tiene derecho a toda el agua que penetre por la toma de la acequia, pero si un regante decide separarse de la comunidad o vender su tierra, no puede llevarse la porción de agua de la que disfrutaba. Artículo 4": "La Comunidad tiene derecho a toda el agua derivada que entre en su acequia Mayor por la toma o boquera de la Presa que tiene construida en el río Segura, paraje de la Algaida, hasta llegar a las particiones de Lorquí,...”. Artículo $8^{\circ}$ : Ningún regante o usuario que forme parte de de la Comunidad podrá separarse de ella sin renunciar antes por completo al aprovechamiento de las aguas que la misma utiliza,...". El juntamento general es el máximo responsable del gobierno de la comunidad en la que participan los usuarios de forma proporcional a la extensión de 
terreno que tengan derecho a regar (obligaciones), en cierto modo es una gobernanza colegiada. Artículo 13: La Comunidad, reunida en Juntamento o Junta General, asume el poder que en aquella existe. Para su gobierno y régimen se establecen, con arreglo a ley, el Sindicato y Jurado de Riegos".

\section{Heredamiento Regante \\ - DE -

Redactados por la respetabie Comisión designada al efecto los Proyectos de Ordenanzas y Reglamentos del Sindicato y Jurado de Riegos y señalado el dia 15 del actual y hora de las nueve para su aprobación definitiva en Juntamento extraordínario, ha acordado la Junta representativa que presido imprimir y repartir dichos proyectos entre los Sres. Hacendados, para que puedan estudiarlos detenida y concienzudamente, á objeto de proponer las enmiendas ó modificaciones que estimen favorables al interés común.

En su virtud, cumpliendo el susodicho acuerdo, tengo el honor de remitir á V. adjunto un ejemplar de los referidos Proyectos.

A la vez, y por encargo de la citada Junta, me permito encarecerle la puntual asistencia al aludido Juntamento de 15 del actual, por ser necesaria para su validez la concurrencia de la representaciòn de la mayoría absoluta de la propiedad que reunen los partícipes de la Comunidad, según está determinado en el caso $6 .^{\circ}$ de la Instruceión aprobada por R. O. de 25 de Junio de 1884.

Dios guarde à $V$. muchos años.

Molina 5 de Abril de 1909.

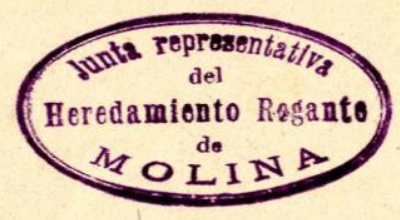

El Alcalde-Presidente,
Antonio Sopez Riquelme.

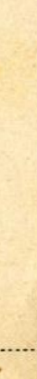

$\int_{r} a$

Fig.6. Impreso enviado en 1909 a los hacendados del Heredamiento Regante de Molina de los proyectos de Ordenanzas y Reglamentos del Sindicato y Jurado de Riegos.

\section{Conclusiones y propuestas.}

Durante siglos se fueron construyendo los paisajes del regadío en la Vega Alta del Segura. Sometidos al régimen del rio Segura con acusados estiajes, sólo las tierras inmediatas al rio practicarían cultivos de huerta todo el año, así como el cultivo del arroz en el tramo superior dónde disponen de todo el caudal por el escaso sangrado anterior. El resto desarrolló una agricultura de secano con árboles frutales típicos mediterráneos (higueras, almendro y vid), y otros. 
La regulación del régimen del rio con la construcción de los grandes embalses es la que permite la aparición de los paisajes que asociamos a las huertas tradicionales, sea en el fondo del valle o en las laderas inmediatas. La pérdida de significado económico por la fragmentación de la propiedad, en explotaciones que ya eran reducidas por la presión demográfica que siempre han sufrido, y que lo solventaban con una intensidad de cultivo que sólo las buenas temperaturas y el agua posibilitaban, fue el primer síntoma de posibles cambios en estos paisajes. El crecimiento urbano, las nuevas necesidades de instalaciones de todo tipo, han presionado sobre unas tierras de alto valor agronómico en decadencia, pero de elevado valor patrimonial. Las que por su microclima aún subsisten económicamente, no se sabe hasta cuándo, pero lo cierto es que estos paisajes son el verdadero legado de nuestros antecesores, son nuestro patrimonio y es nuestra cultura, el resultado de una cultura del agua que debemos de ser capaces de valorar y reconocer.

\section{Agradecimientos}

Proyecto de Investigación 12011 PHCS/09 "El interés geográfico de la ordenación territorial en el Sureste de España, auspiciada por el Trasvase Tajo-Segura" de la Fundación Séneca. Plan de Ciencia y Tecnología de la Región de Murcia. España.

\section{Referencias}

Heredamiento de Aguas de la Fuente Grande. Ricote (Murcia). (1991) Ordenanzas de su regulación y usos. pp. 63

Gil Meseguer, E.; García Martínez, P. J.; Gómez Espín, J. Ma.; Almela Pérez, R. (2014): El dinamismo del regadío de Pulpí. Comunidad de Regantes de Pulpí. Murcia, pp. 222.

Glick, T. F. (1988): Regadío y sociedad en la V alencia medieval. Del Cenia al Segura. Valencia, pp 413

Gómez Espín, J.Ma. (2004): Aprovechamiento integral del agua en la Rambla de Nogalte (Puerto Lumbreras - Murcia). Universidad de Murcia. Murcia, pp.190.

Hermosilla Plá, J. (Dir) (2010): Los regadios históricos españoles. Paisajes culturales, paisajes sostenibles. Ministerio de Medio Ambiente, Medio Rural y Marino. Madrid, pp. 608 .

Maass, A.; Anderson, R.L. (2010): Los desiertos reverdecerán. Estudio comparativo de la gestión del riego en el Mediterráneo español y en el Oeste norteamericano. Generalitat Valenciana, pp. 436

Palerm Viqueira, J. (editor) (2002): Antología sobre pequeño riego. Volumen III. Sistemas de riego no convencionales. Colegio de Posgraduados. México, pp. 372

Palerm Viqueira, J.; Martínez Saldaña, T. (Coordinadores) (2000): Antología sobre pequeño riego. Volumen II. Organizaciones autogestivas. Plaza y Valdés editores. México, pp. 467

Palerm Viqueira, J.; Martínez Saldaña, T. (Editores) (2009): Aventuras con el Agua. La administración del agua de riego. Historia y Teoría. CONACYT. Colegio de Posgraduados. Texcoco México, pp. 435

Rivera, J. A. (2009): La cultura de la acequia. Agua, tierra y comunidad en el Suroeste de los Estados Unidos de América. Universitat de València, pp. 309 